\title{
An Outlook on Magnesium-Based Biodegradable Implants
}

\section{Bobby Kannan $\mathbf{M}^{*}$}

Biomaterials and Engineering Materials (BEM) Laboratory, School of Engineering and Physical Sciences, James Cook University, Townsville, Queensland 4811, Australia

In this ageing population, the use of implants for repair of bone fractures is increasing rapidly. Mini-implants such as plates and screws are often used for bone fracture healing. Currently non-degradable implants made of metallic materials such as stainless steel, titanium alloys or chromium-cobalt alloys are commonly used [1]. However, the long-term exposure of these non-degradable implants greatly increases the risk of complications such as foreign body reactions and inflammation due to the release of metal ions or particles as a result of corrosion/wear [2]. This necessitates a secondary surgical process to remove the implant after healing of the tissues. In fact, repeat surgery is a risk and also increases the costs to both the patient and the health care system.

The problems associated with non-degradable implants have led to a growing interest in biodegradable materials. The idea is that the implant remains in the body i.e., serving its purpose during the healing process, and then naturally degrades in the body fluid and excretes without any complication. Biocompatible and biodegradable polymers e.g. polylactide, polyglycolide and their copolymers are commercially available, but the mechanical strength of these polymers is too low to be used in orthopaedic load-bearing applications [3].

Magnesium, a light weight metallic materials, is a potential material for biodegradable implant applications, since magnesium degrades in body fluid and the degradation product is non-toxic and soluble in body fluid [3]. Importantly, magnesium has similar mechanical properties to natural bone, especially the compressive yield strength of magnesium is closer to that of natural bone than that of the commonly used metallic biomaterials [4]. This attractive property could also avoid the risk of stress shielding effect which generally delays the bone healing process [3]. It has to be noted that magnesium is basically essential to human metabolism and moreover research work has shown that magnesium contributes to bone strength [5]. Magnesium is also a co-factor for many enzymes, and stabilizes the structures of DNA and RNA [6]. Although it is reported that high level of magnesium $(>1.05 \mathrm{mmol} / \mathrm{L})$ in the human body could lead to complications, hyper-magnesium is rare due to efficient excretion of magnesium products in urine [7].

Due to the high degradation rate of pure magnesium in near neutral $\mathrm{pH}$ and high chloride concentration of body fluid, magnesium cannot be used as an implant in its purest form. The high electronegative potential of magnesium and the non-protective degradation product (oxide/hydroxide) contribute to its high degradation rate. The extremely high degradation rate of magnesium in body fluid not only dissolves the implant before the tissues sufficiently heal, but it also creates hydrogen (a cathodic reaction) gas pockets which potentially affect the healing process [3]. The other consequent problem as a result of the high degradation rate of magnesium is the potential loss of mechanical integrity during service. Although temporary implants are expected to degrade at a slow rate, they need to possess the desired strength in the initial period of healing process. Generally, implant materials are subjected to various modes of loading and as a result can cause failure of implants [8]. Importantly, stress when assisted with degradation can cause catastrophic failure in certain metallic materials. The process is commonly known as Environment-Assisted Cracking (EAC). This phenomenon is particularly relevant for biodegradable biomaterials and is critical to note that magnesium undergo EAC in chloride-containing environments [9].

Alloying is one of the widely used methods to decrease the degradation rate of metallic materials. In the last five years, a number of magnesium alloys have been tested under in-vitro conditions to understand their degradation behaviour and mechanisms [10-14]. $\mathrm{AZ}$ (aluminium, zinc) series magnesium alloys are the most highly researched material due to their commercial availability $[11,13]$. Magnesium-calcium alloys and rare-earths containing magnesium alloys e.g. ZE41, WE43, WE54 and LAE442 (containing rare-earth mixtures such as cerium, lanthanum, ytterbium, neodymium and praseodymium) have also been tested $[12,14,15]$. However, the enhancement in the degradation resistance of magnesium due to alloying has not been encouraging. Due to the high electronegative potential of magnesium (-2.4 $\mathrm{V}$ with respect to hydrogen electrode) and its poor passivating tendency, alloying alone may not provide the required protection. Moreover, the inhomogeneous microstructures in these alloys can cause localized degradation $[12,16]$. It is critical to minimize the localized degradation of magnesium-based biodegradable biomaterials, at least during the intial stage of service, for better mechanical integrity.

Surface coating is a potential method to minimize the initial localized degradation resistance of magnesium alloys. Importantly, the coating should be biocompatible and biodegradable with degradation rate lower than that of magnesium alloys. Recent studies on calcium phosphate and polymer coatings on magnesium alloys have shown significant improvement in the general and localized degradation resistance [17-19]. Hence, the outlook for magnesium-based biodegradable implants seems promising.

\section{References}

1. Niinomi M (2002) Recent metallic materials for biomedical applications. Metall Mater Trans A 33: 477-486.

2. Jacobs JJ, Gilbert JL, Urban RM (1998) Corrosion of metal orthopaedic implants. J Bone Joint Surg Am 80: 268-282.

3. Witte F, Hort N, Vogt C, Cohen S, Kainer KU, et al. (2008) Degradable biomaterials based on magnesium corrosion. Curr Opin Solid St M 12: 63-72.

4. Staiger MP, Pietak AM, Huadmai J, Dias G (2006) Magnesium and its alloys as orthopedic biomaterials: a review. Biomaterials 27: 1728-1734.

5. Okuma T (2001) Magnesium and bone strength. Nutrition 17: 679-680.

*Corresponding author: Bobby Kannan M, Biomaterials and Engineering Materials (BEM) Laboratory, School of Engineering and Physical Sciences, James Cook University, Townsville, Queensland 4811, Australia, Tel: +61 74781 5080; Fax: +61 74781 6788; E-mail: bobby.mathan@jcu.edu.au

Received January 14, 2013; Accepted January 15, 2013; Published January 23 2013

Citation: Bobby Kannan M (2013) An Outlook on Magnesium-Based Biodegradable Implants. J Material Sci Eng 2: e108. doi:10.4172/2169-0022.1000e108

Copyright: (c) 2013 Bobby Kannan M. This is an open-access article distributed under the terms of the Creative Commons Attribution License, which permits unrestricted use, distribution, and reproduction in any medium, provided the original author and source are credited. 
Citation: Bobby Kannan M (2013) An Outlook on Magnesium-Based Biodegradable Implants. J Material Sci Eng 2: e108. doi:10.4172/21690022.1000e108

Page 2 of 2

6. Hartwig A (2001) Role of magnesium in genomic stability. Mutat Res 475: 113 121

7. Saris NE, Mervaala E, Karppanen H, Khawaja JA, Lewenstam A (2000) Magnesium. An update on physiological, clinical and analytical aspects. Clin Chim Acta 294: 1-26.

8. Teoh SH (2000) Fatigue of biomaterials: a review. Int J Fatigue 22: 825-837.

9. Winzer N, Atrens A, Song G, Ghali E, Dietzel W, et al. (2005) A Critical Review of the Stress Corrosion Cracking (SCC) of Magnesium Alloys. Advanced Engineering Materials 7: 659-693.

10. Kannan MB, Raman RK (2008) In vitro degradation and mechanical integrity of calcium-containing magnesium alloys in modified-simulated body fluid. Biomaterials 29: 2306-2314

11. Bobby Kannan M, Singh RK (2010) A mechanistic study of in vitro degradation of magnesium alloy using electrochemical techniques. J Biomed Mater Res A 93: $1050-1055$

12. Walter R, Kannan MB (2011) In-vitro degradation behaviour of WE54 magnesium alloy in simulated body fluid. Mater Lett 65: 748-750.
13. Song GL (2007) Control of biodegradation of biocompatable magnesium alloys. Corros Sci 49: 1696-1701.

14. Rettig R, Virtanen S (2008) Time-dependent electrochemical characterization of the corrosion of a magnesium rare-earth alloy in simulated body fluids. J Biomed Mater Res A 85: 167-175.

15. Kim WC, Kim JG, Lee JY, Seok HK (2008) Influence of Ca on the corrosion properties of magnesium for biomaterials. Mater Lett 62: 4146-4148.

16. Kannan MB (2010) Influence of microstructure on the in-vitro degradation behaviour of magnesium alloys. Mater Lett 64: 739-742.

17. Kannan MB (2012) Enhancing the performance of calcium phosphate coating on a magnesium alloy for bioimplant applications. Mater Lett 76: 109-112.

18. Kannan MB, Wallipa O (2013) Potentiostatic pulse-deposition of calcium phosphate on magnesium alloy for temporary implant applications - An in vitro corrosion study. Mat Sci Eng C-Biomim 33: 675-679.

19. Alabbasi A, Liyanaarachchi S, Kannan MB (2012) Polylactic acid coating on a biodegradable magnesium alloy: An in vitro degradation study by electrochemical impedance spectroscopy. Thin Solid Films 520: 6841-6844. 